\title{
Integrated Extrusion-Shear Forming Process of the Solid-State Recycled AZ80 Magnesium Alloy via Hot Press Sintering
}

\author{
Bing $\mathrm{Li}^{1} \cdot$ Bugang Teng ${ }^{1,2} \cdot$ Baoting Zhang ${ }^{1}$
}

Received: 12 August 2019 / Revised: 14 October 2019 / Published online: 3 January 2020

(c) The Chinese Society for Metals (CSM) and Springer-Verlag GmbH Germany, part of Springer Nature 2020

\begin{abstract}
The consolidation recycled AZ80 billets were successfully fabricated through the cold press and hot press sintering of the AZ80 metal chips. The consolidation recycled billets sintered at $350{ }^{\circ} \mathrm{C}$ present the comparable compressive properties and inferior tensile properties compared with the initial cast billets. The defects in the consolidation recycled billet were inclined to propagate along the bond interface between the metal chips during tension, which resulted in the inferior tensile properties of the recycled billets. The recycled billets were then subjected to the integrated extrusion-shear (ES) process. The homogeneous finer dynamic recrystallization grains with an average grain size of $6 \mu \mathrm{m}$ can be obtained in the shear deformation zone and extrusion sizing zone through integrated ES process at $300^{\circ} \mathrm{C}$ with an extrusion velocity of $0.6 \mathrm{~mm} / \mathrm{s}$. The recycled billets after integrated ES forming process present rival tensile properties compared with the initial cast billets after integrated ES forming with the same extrusion parameters, which can be ascribed to that the integrated ES forming can nearly eliminate the defects through the severe compressive and shear strain. The solid-state recycling process through hot press sintering and subsequent integrated ES process can fabricate the consolidation recycled AZ80 rod, which demonstrates the comparable tensile properties with the cast-extrusion rod.
\end{abstract}

Keywords Solid-state recycling $\cdot$ Hot press sintering $\cdot$ Integrated extrusion-shear forming $\cdot$ Metal chips $\cdot$ Mechanical properties

\section{Introduction}

The Mg alloy has attracted more attention due to its high specific stiffness, high specific strength and environmental and easy recycling $[1,2]$. The $\mathrm{Mg}$ alloy has been widely employed in vehicles, communication and consumer electronics industry [3-5]. The rapid demand for the Mg alloy results in the massive losses and waste during the manufacturing process of $\mathrm{Mg}$ alloy [6,7]. Thus, it is of vital importance to recycle the $\mathrm{Mg}$ alloy through the effective way.

Available online at https://link.springer.com/journal/40195

Bugang Teng

bgteng@hit.edu.cn

1 School of Materials Science and Engineering, Harbin Institute of Technology, Harbin 150001, China

2 National Key Laboratory for Precision Hot Processing of Metals, Harbin Institute of Technology, Harbin 150001, China
The conventional recycled method of the $\mathrm{Mg}$ alloy was liquid recycling, which requires remelting $\mathrm{Mg}$ scraps into the liquid state $[6,8]$. The melting process consumed the fuels and exhausts the hazardous gas and required addition of the refiners and covering agents [9]. However, the oxidation and burning loss of the metal scraps occur during the remelting process, which leads to the lower recycling rate. The solidstate recycling refers to that the metal scraps were consolidated recycled without remelting process [10], and the metal scraps were bonded through the atom diffusion and interface reaction at elevated temperature which was below the melting temperature. It is documented that the disintegration of outer surface occurs in the consolidation billets only through cold press although the billets demonstrate the relatively high compactness, which indicates that the only high compressive forces are not enough to obtain the effective chip bonding [11]. The additional shear force can be implemented on cold- or hot-pressed billets to achieve full consolidation recycled billets with superior mechanical properties, such as extrusion process [12]. Wei et al. [13] prepared the $\mathrm{AZ} 31 / \mathrm{Al}_{2} \mathrm{O}_{3}$ composites through solid-phase synthesis and 
evaluated the microstructure and properties of the prepared $\mathrm{AZ31} / \mathrm{Al}_{2} \mathrm{O}_{3}$ composites. Furthermore, Zhu et al. [14] also fabricated the AZ31-Ce by multi-pass solid-phase synthesis and found that the tensile strength and elongation of the AZ31-Ce magnesium alloy significantly improved with the increase in the extrusion passes. Thein et al. [15] fabricated the nanostructured $\mathrm{Mg}-5 \mathrm{AL}-x \mathrm{AlN}$ composite from the $\mathrm{Mg}$ chips through the hot extrusion process. Ji et al. [16] fabricated the $\mathrm{Mg}-2.4 \mathrm{Nd}-0.6 \mathrm{Zn}-0.6 \mathrm{Zr}$ recycled-extrusion alloys which exhibited the superior mechanical properties. Anilchandra and Surappa [17] recycled the Mg alloy through cold press in vacuum and hot extrusion in the temperature range of $250-400{ }^{\circ} \mathrm{C}$, and tensile yield strength and ultimate tensile strength were improved by $15 \%$ compared with the raw materials. Chino et al. [18, 19] recycled the AZ31 Mg alloy metal chips through the hot extrusion at $230{ }^{\circ} \mathrm{C}$, and the uniformly dispersive oxidation phases contributed to the elevated tensile strength of the extrusion recycled billets compared with cast-extrusion billets. Chino et al. [20] also recycled the $\mathrm{Mg}-\mathrm{Al}-\mathrm{Ca}$ alloy through the hot extrusion at $400{ }^{\circ} \mathrm{C}$.

Orlov et al. [21] fabricated the ZK60 Mg alloy rod of $16 \mathrm{~mm}$ in diameter and $4 \mathrm{~m}$ in length through the successive extrusion-shear (ES) after the extrusion process and concluded that the compressive strength increased by $50 \%$ and the fracture mechanism shifted from the brittle fracture to ductile fracture. Furthermore, Orlov et al. [22] also studied the corrosion resistance of the Mg alloy after ES process and concluded that the corrosion resistance of the $\mathrm{Mg}$ alloy was improved after ES process. Vinogradov et al. [23] investigated the fatigue resistance of the ZK60 Mg alloy after ES process, and the results demonstrated that the high cycle fatigue limit under the symmetrical push-pull load was $160 \mathrm{MPa}$, which was twice than that of the raw materials. Peng et al. [24] proposed that the physical bonding from the plastic deformation and the atoms diffusion between metal chips can facilitate the consolidation recycling of the $\mathrm{Mg}$ alloy. The severe plastic deformation (SPD) process can be also implemented during the solid-state recycling process to achieve the full densification and superior bond properties between metal chips and eliminate the holes or defects in the recycled billets. However, the integrated ES process of the recycled billets from metal chips was hardly studied. Therefore, the integrated ES process was carried out to improve the density and mechanical properties of the recycled billets.

The study systematically investigated the solid-state recycling of the AZ80 Mg alloy through the cold- and hotpressed sintering billets, and the effects of the sintering temperature on the recycled billets were also studied. Furthermore, the integrated ES process was also implemented on the consolidation recycled billets. The microstructure evolution and mechanical properties of the consolidation recycled billets during the integrated ES forming process were also studied.

\section{Materials and Experimental Procedures}

\subsection{Initial Materials and Consolidation Recycled Billets}

The cast AZ80 Mg alloy was selected and used as a reference material in this study. The metal chips with $1-2 \mathrm{~mm}$ of width, $4-5 \mathrm{~mm}$ of length and $<0.1 \mathrm{~mm}$ of thickness were machined from the cast AZ80 Mg alloy ingot. The metal chips were rinsed with the distilled water and chemically cleaned with the alcohol and acetone under ultrasonic wave to eliminate the effects of the surface impurities and grease contaminations. The schematic diagram and experimental apparatus of the mold for the cold and hot press sintering are demonstrated in Fig. 1a, b. The same weight of the metal chip was selected in each recycling process. The metal scraps were poured into the mold and firstly subjected to the cold press under the pressure of $300 \mathrm{MPa}$ for $2 \mathrm{~min}$, and (a)

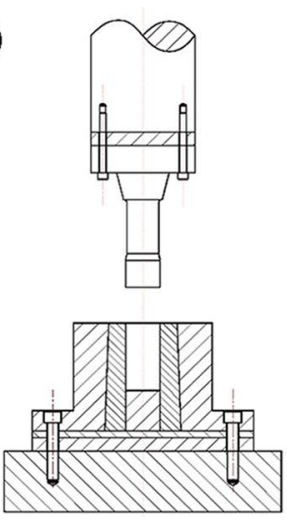

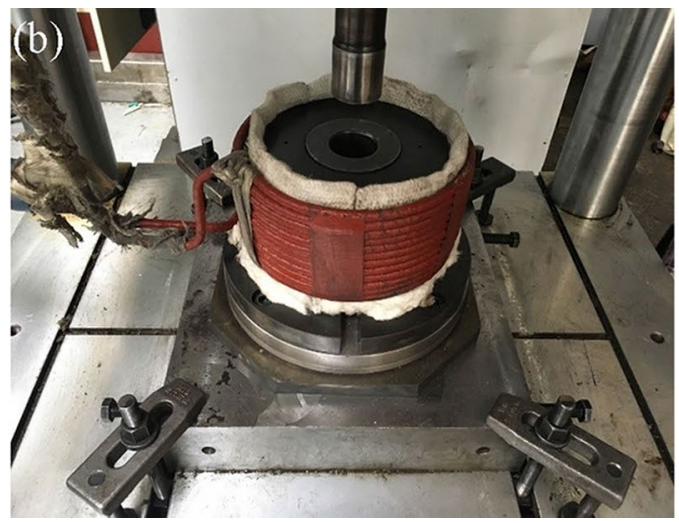

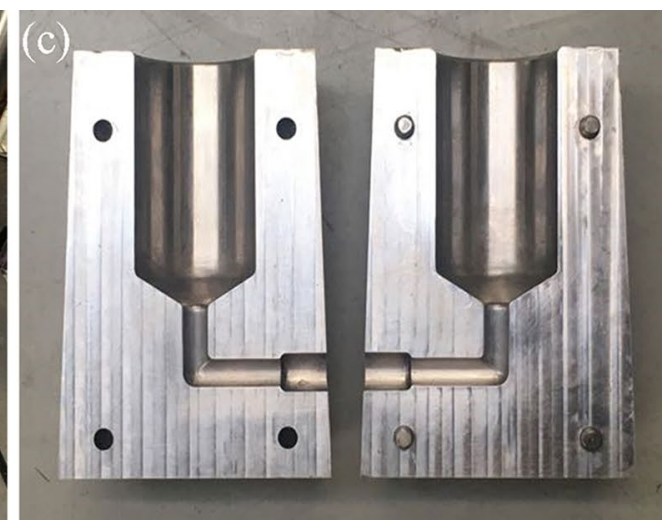

Fig. 1 Images of a the schematic diagram, $\mathbf{b}$ the experimental apparatus, $\mathbf{c}$ the mold for integrated ES process 
thus, the cold-pressed billets with $50 \mathrm{~mm}$ in diameter and $30 \mathrm{~mm}$ in height can be obtained, as illustrated in Fig. 2a. Then, the cold-pressed billets were subjected to the hot press sintering process to obtain the solid-state recycled billets, and the effect of the sintering temperature on the mechanical properties of the consolidation recycled billets was studied. The consolidation recycled billets after hot press sintering process are shown in Fig. 2b.

\subsection{Integrated ES Forming Process}

The integrated ES process with different parameters was implemented on the consolidation recycled billet. The mold for the integrated ES process is illustrated in Fig. 1c, and thus, the extrusion rods with $10 \mathrm{~mm}$ in diameter were obtained and the extrusion ratio was 25 . The lubricant $\left(\mathrm{MoS}_{2}\right.$ synthetic grease) was used in the integrated extrusion-shear deformation process. The effects of the extrusion parameters were also investigated in this study, and the extrusion parameters were set in the temperature range from 300 to $450{ }^{\circ} \mathrm{C}$ and extrusion velocity from 0.2 to $1.4 \mathrm{~mm} / \mathrm{s}$. The extrusion billets with different extrusion parameters are demonstrated in Fig. 2c-f. The extrusion billets after the integrated ES forming can be divided into three zones: compression reduction zone (CRZ), extrusion sizing zone (ESZ) and shear deformation zone (SDZ), as illustrated in Fig. 2g.

\subsection{Material Characterization and Mechanical Property Evaluation}

The samples for the optical microstructure (OM) and scan electron microscope (SEM) observation were wire electrical-discharge machined from the consolidation recycled billets and CRZ, SDZ and ERZ of the extrusion billets. The samples were chemically etched in the solution composed of $5 \mathrm{~g}$ picric acid, $5 \mathrm{ml}$ alcohol, $100 \mathrm{ml}$ acetic acid and $10 \mathrm{ml}$ distilled water. The OM observations were carried out by the Leica DMI3000M optical microscope, and the SEM observations were conducted using the Zeiss Supra 55. In addition, the cylinder compression samples with $6 \mathrm{~mm}$ in diameter and $9 \mathrm{~mm}$ in height were turned from the recycled billets and different zones of the extrusion billets. Furthermore, the cylinder tension samples with $15 \mathrm{~mm}$ in gauge length and $3 \mathrm{~mm}$ in diameter were also turned from the cast and recycled billets for the comparison. The compression and tension tests at room temperature were conducted using the Shimadzu Autograph AG-X plus test machinery, and three repeated compression/tension tests for each billet were required to guarantee the repeatability.

\section{Results and Discussion}

\subsection{Consolidation Recycling of the Metal Chips}

The cold-pressed billets from the metal chips are illustrated in Fig. 2a, and the measured density was approximately $78.64 \%$ with reference to the cast billets. The billets sintered
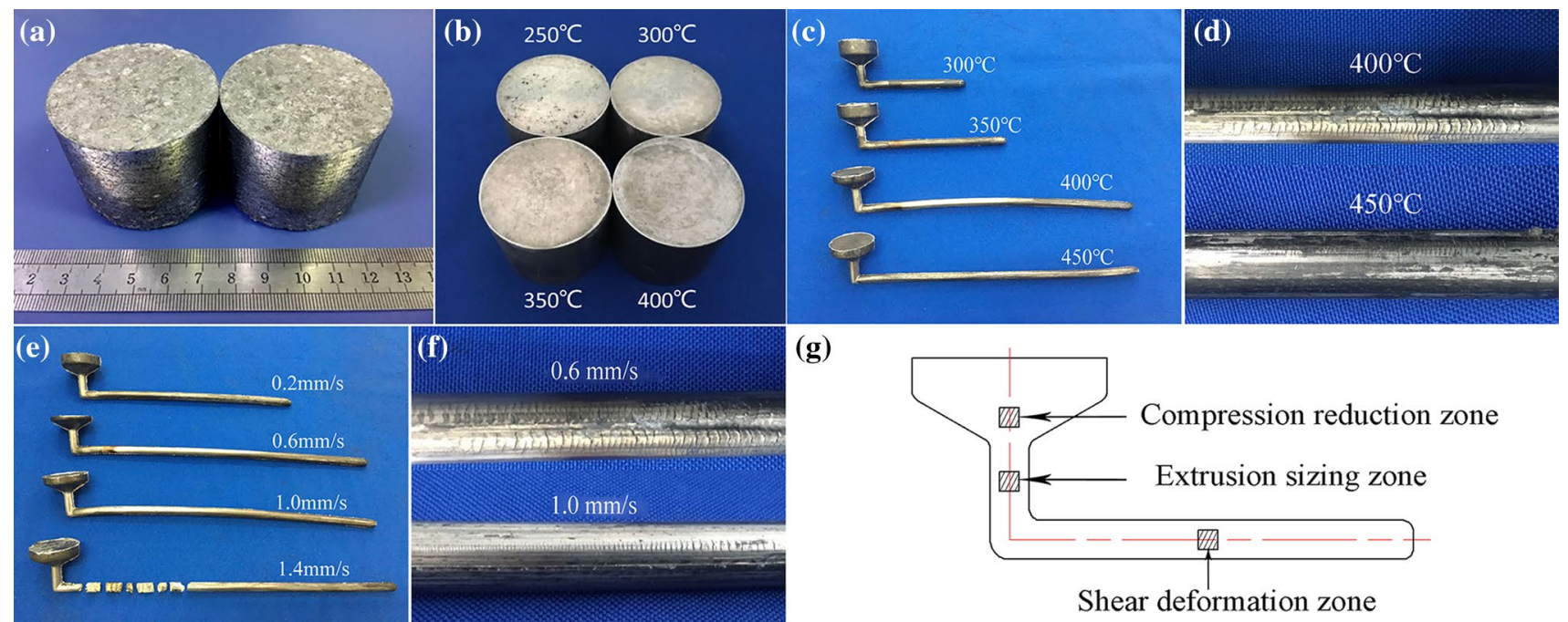

(g)

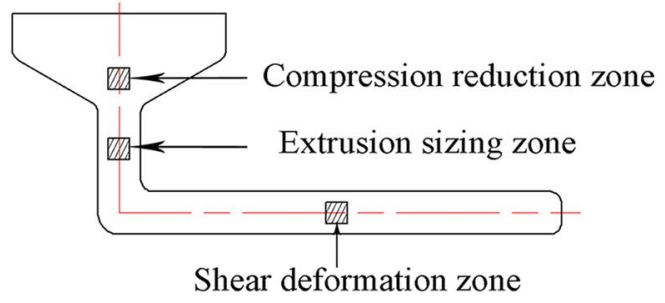

Fig. 2 Images of the a cold-pressed billets, $\mathbf{b}$ hot press sintering billets, $\mathbf{c}$ the integrated ES-formed rod with different temperatures, $\mathbf{d}$ the integrated ES-formed rod with extrusion temperature of $400{ }^{\circ} \mathrm{C}$ and $450{ }^{\circ} \mathrm{C}$, e the integrated ES-formed rod with different extrusion velocities, $\mathbf{f}$ the integrated ES-formed extrusion rod with extrusion velocities of $0.6 \mathrm{~mm} / \mathrm{s}$ and $1.0 \mathrm{~mm} / \mathrm{s}, \mathbf{g}$ the schematic diagram of the billets after integrated ES forming 
at different temperatures are demonstrated in Fig. $2 b$, and the corresponding OM and SEM images of the consolidation recycled billets at different sintering temperatures are illustrated in Fig. 3. The densifications of the billets recycled at $250{ }^{\circ} \mathrm{C}, 300{ }^{\circ} \mathrm{C}, 350{ }^{\circ} \mathrm{C}$ and $400{ }^{\circ} \mathrm{C}$ were $99.43 \%, 99.54 \%$, $99.62 \%$ and $99.66 \%$, respectively. The bond interface of the metal chips can be clearly observed, as demonstrated in Fig. 3a, c, e, g. The majority of cracks occurred at the bond interface between metal chips in the consolidation recycled billets. Furthermore, the strip $\beta-\mathrm{Mg}_{17} \mathrm{Al}_{12}$ and $\mathrm{Al}_{8} \mathrm{Mn}_{5}$ phase precipitated at the grain boundaries, as presented in Fig. $3 b, d, f, h$, and the fraction of the strip $\beta-\mathrm{Mg}_{17} \mathrm{Al}_{12}$ phase decreased as the sintering temperature was elevated. Compared with the billets sintered at $250^{\circ} \mathrm{C}$, the coarse deformed grains were surrounded with the finer dynamic recrystallization (DRX) grains (average grain size $<10 \mu \mathrm{m}$ ) in the billets sintered at $300{ }^{\circ} \mathrm{C}$, which indicated that the DRX occurred during the consolidation sintering at $300{ }^{\circ} \mathrm{C}$. The compressive pressure and heat input facilitate the DRX process at the bond interface to some extent, and thus, the finer grains can be observed at the bond interface between metal chips. The fraction of the DRX grains increased as the sintering temperature was elevated to $350{ }^{\circ} \mathrm{C}$, and the limited fraction of the strip $\beta$-phases precipitated within $\alpha$-Mg grains. However, the grains grew significantly as the sintering temperature increased to $400{ }^{\circ} \mathrm{C}$, as illustrated in Fig. $3 \mathrm{~g}$, and the massive lamellar $\beta$-phases precipitated within the $\alpha$-Mg grains.

The compression and tensile properties of the consolidation recycled billets are shown in Fig. 4. The ultimate compression strength (UCS) of the consolidation recycled billets increased from 328.16 to $360.51 \mathrm{MPa}$, and the compression failure strain (CFS) increased from 6.74 to $14.08 \%$ as the consolidation sintering temperature was elevated from 250 to $350{ }^{\circ} \mathrm{C}$, as illustrated in Fig. 4a. The atom diffusions were enhanced as the consolidation sintering temperature increased, which contributed to the close bonding between the metal chips, and thus, the compression strength and compression failure strain were simultaneously elevated with the increase in sintering temperature. The UCS slightly improved; however, the CFS declined as the sintering temperature increased to $400{ }^{\circ} \mathrm{C}$. The precipitated lamellar $\beta$-phases within the $\alpha$-Mg grains can strengthen the consolidation billets, which can compensate for the weakening effect of the grain growth. However, the consolidation recycled billets demonstrated the inferior tensile properties compared with the cast billets, which can be ascribed to that the cracks at the bond interface were inclined to propagate along the weakly bonded interface between the metal chips during tension. The fracture morphologies in Fig. 5a, c illustrated that the cleavage plane and river-like patterns indicating the brittle fracture can be observed in the fracture of the cast samples. The fracture morphologies in Fig. 5b, d indicated the weakly bonded interface between metal chips.
Compared with the cast samples, the consolidation recycled billets demonstrated the inferior tensile properties and superior compressive properties.

\subsection{Effects of the Extrusion Parameters on the Consolidation Recycled Billets}

The recycled billets were subjected to the integrated ES forming with different extrusion parameters, and the recycled billets after integrated ES forming were denoted as recycled-extrusion billets in this study. Similarly, the cast billets after the integrated ES forming process were denoted as the cast-extrusion billets. The lower extrusion temperature or extrusion velocity was not conducive to the better surface quality, as demonstrated in Fig. 2d, f. The OM observations of the recycled-extrusion billets with different extrusion temperatures are illustrated in Fig. 6. The bimodal microstructure, in which the coarse deformed grains $(\sim 20 \mu \mathrm{m})$ were surrounded with the finer DRX grains $(<5 \mu \mathrm{m})$, can be clearly observed at the CRZ in the recycled-extrusion billets extruded at $300{ }^{\circ} \mathrm{C}$. Furthermore, the bond interface and the $\beta$-phases were elongated along the extrusion direction (ED). The finer DRX grains preferably nucleated around the bond interface, as illustrated in Fig. 6a, d, which can be ascribed to that the oxidation particles can provide the numerous DRX nucleation site. The lower extrusion temperature can effectively restrain the growth of the DRX grains. The growth of the DRX grains can be obviously observed as the extrusion temperature was elevated to $350{ }^{\circ} \mathrm{C}$, as presented in Fig. $6 \mathrm{~d}$. The $\beta$-phases dissolved into the $\alpha$-Mg matrix as the extrusion temperature increased to $400{ }^{\circ} \mathrm{C}$ or $450{ }^{\circ} \mathrm{C}$, and the grains significantly grew due to the higher extrusion temperature, as demonstrated in Fig. 6g, j.

The bimodal microstructure observed in the CRZ has transformed into fully fine DRX grains $(\sim 6 \mu \mathrm{m})$ in the ESZ of the recycled billets after ES at $300{ }^{\circ} \mathrm{C}$, as illustrated in Fig. 6b. The strip $\beta$-phases and scattered $\mathrm{Al}_{8} \mathrm{Mn}_{5}$ phases were aligned with the ED in the ESZ, as shown in the SEM images of Fig. 7a. The average size of the finer DRX grains increased to $8 \mu \mathrm{m}$ as the extrusion temperature was elevated to $350{ }^{\circ} \mathrm{C}$. The finer DRX grains significantly grew as the extrusion temperature increased to $400{ }^{\circ} \mathrm{C}$ or $450{ }^{\circ} \mathrm{C}$, as demonstrated in Fig. $6 \mathrm{~g}, \mathrm{~h}, \mathrm{j}, \mathrm{k}$. The strip $\beta$-phases and scattered $\mathrm{Al}_{8} \mathrm{Mn}_{5}$ phases were scarcely observed in the ESZ of the extrusion billets at $400{ }^{\circ} \mathrm{C}$ or $450{ }^{\circ} \mathrm{C}$, as illustrated in Fig. 7c, d.

Figure $6 \mathrm{c}, \mathrm{f}$ demonstrates the $\mathrm{OM}$ observation at SDZ of the recycled-extrusion billets extruded at $300{ }^{\circ} \mathrm{C}$ and $350{ }^{\circ} \mathrm{C}$. The strip $\beta$ - and $\mathrm{Al}_{8} \mathrm{Mn}_{5}$ phases were aligned with the ED, and the finer DRX grains nucleated adjacent to the $\mathrm{Al}_{8} \mathrm{Mn}_{5}$ phases and bond interface through the particlestimulated nucleation (PSN) mechanism. The similar phenomenon occurred as the extrusion temperature increased 


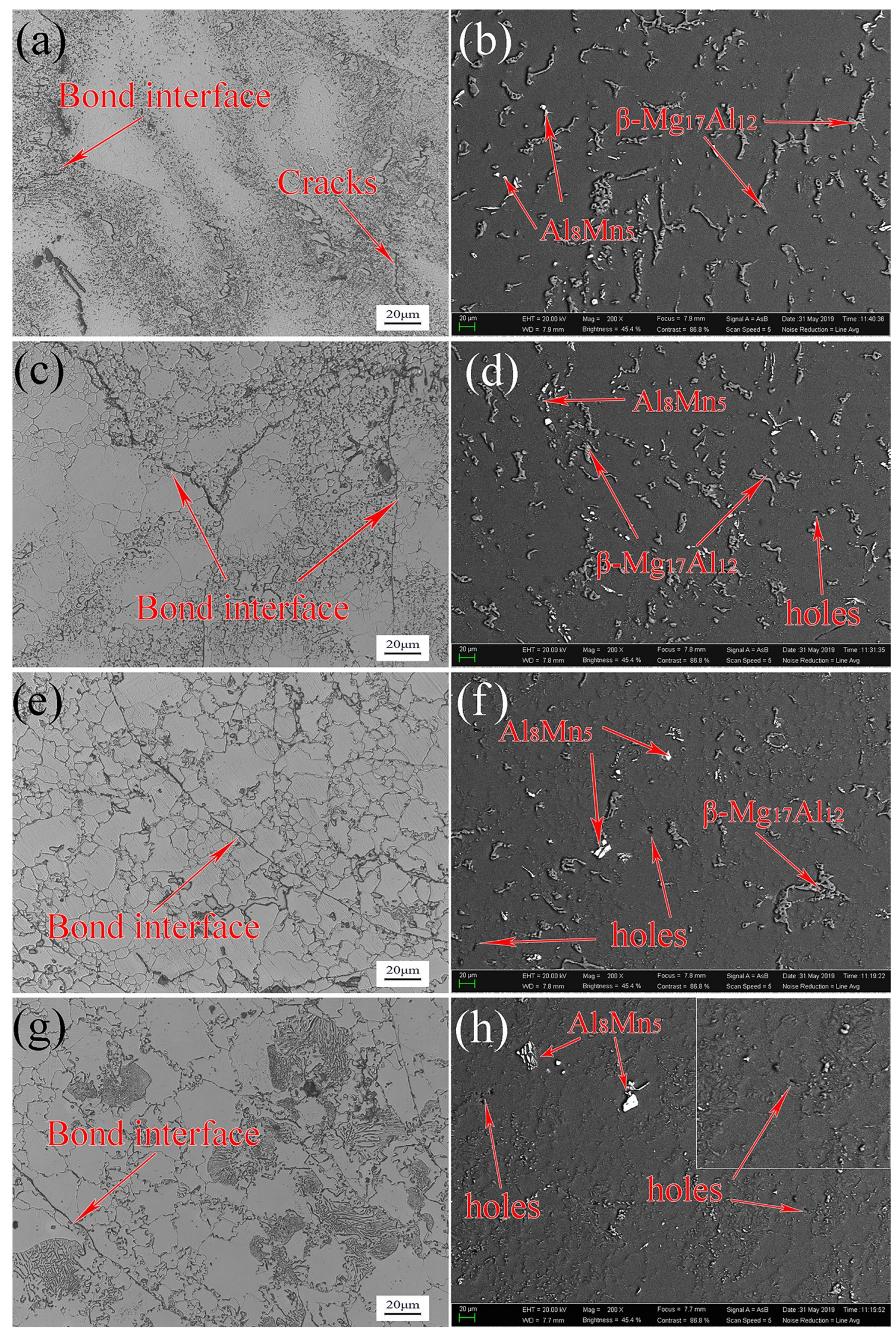

Fig. $3 \mathrm{OM}$ and SEM images of the consolidation recycled billets at different sintering temperatures: a, b $250{ }^{\circ} \mathrm{C}, \mathbf{c}, \mathbf{d ~} 300{ }^{\circ} \mathrm{C}, \mathbf{e}, \mathbf{f} 350{ }^{\circ} \mathrm{C}, \mathbf{g}, \mathbf{h} 400{ }^{\circ} \mathrm{C}$ 

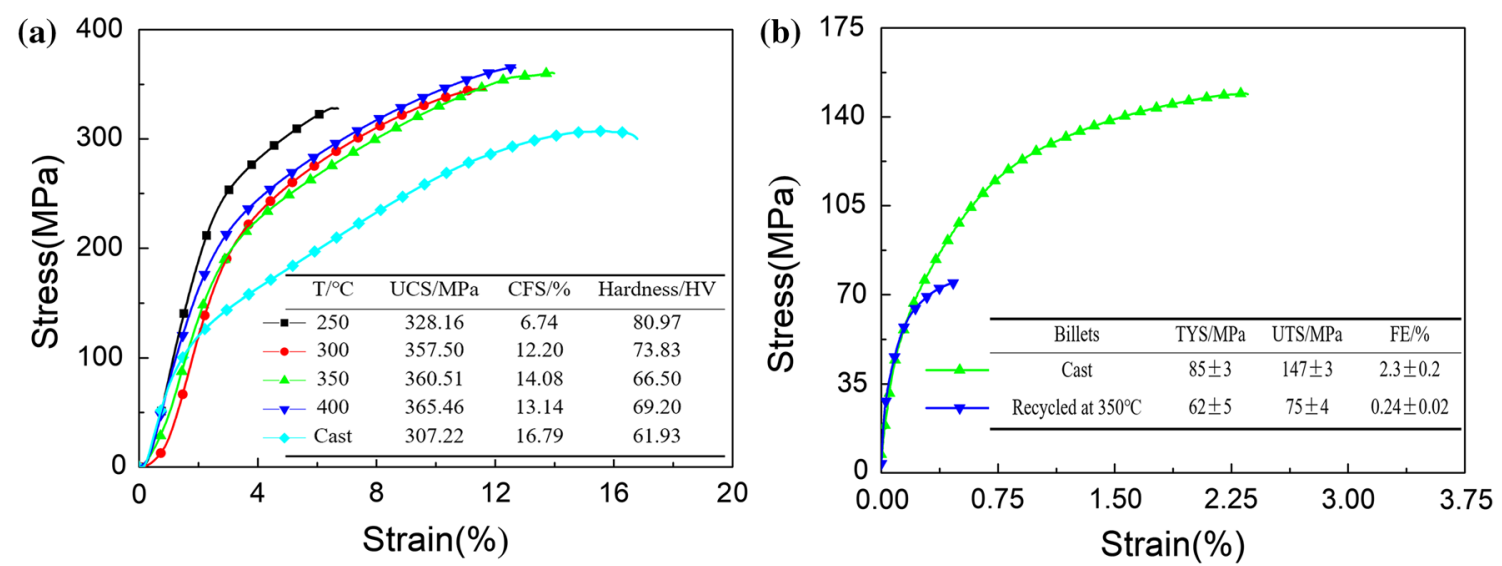

Fig. 4 Stress-strain response of a compression curves the recycled billets at different temperatures, $\mathbf{b}$ tensile curves of cast and recycled billets sintered at $350{ }^{\circ} \mathrm{C}$
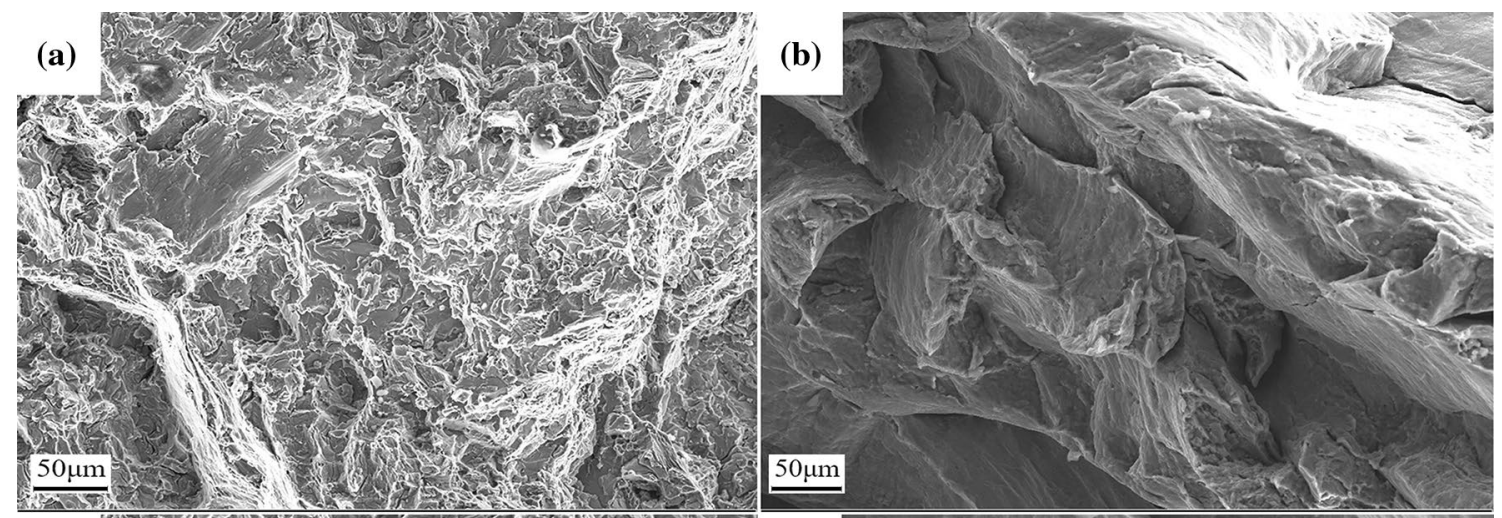

(c)

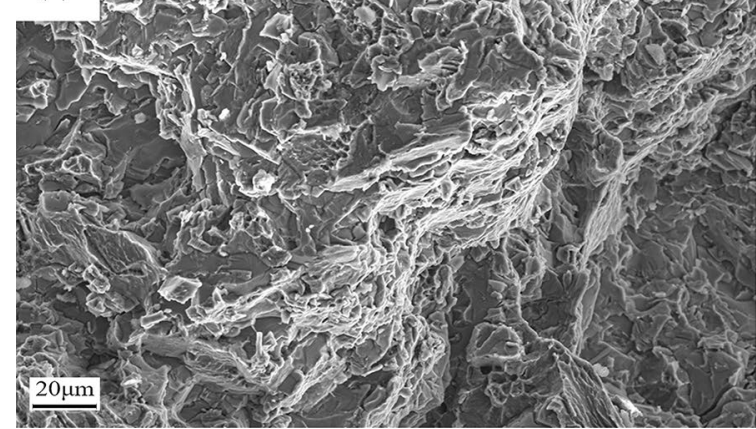

(d)

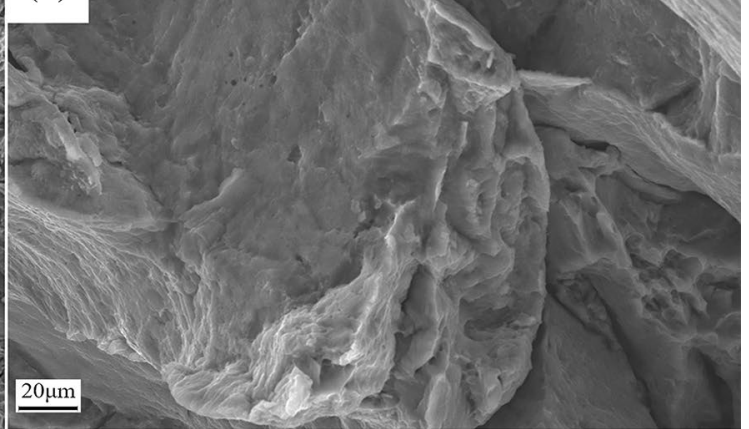

Fig. 5 Tensile fracture morphologies of the $\mathbf{a}, \mathbf{c}$ cast billets, $\mathbf{b}, \mathbf{d}$ recycled billets

to $400{ }^{\circ} \mathrm{C}$ or $450{ }^{\circ} \mathrm{C}$, as illustrated in Fig. 6i, 1 ; however, the average size of the DRX grains increased to $15 \mu \mathrm{m}$ and $18 \mu \mathrm{m}$, respectively. The lamellar $\beta$-phases precipitated within the $\alpha$-Mg matrix as the extrusion temperature increased to $400{ }^{\circ} \mathrm{C}$, which was different from the microstructure at CRZ and ESZ.

The homogeneous finer DRX grains can be obtained in the SDZ of the recycled-extrusion billets extruded at $300{ }^{\circ} \mathrm{C}$.
However, the homogeneous finer DRX grains hardly reflect the effect of the extrusion velocity on the microstructure characteristic if the recycled billets were extruded at $300{ }^{\circ} \mathrm{C}$. Thus, the integrated ES forming process with different extrusion velocities was conducted at $400{ }^{\circ} \mathrm{C}$ to investigate the effects of the extrusion velocity on the microstructure characteristic and mechanical properties of the recycled-extrusion billets. 

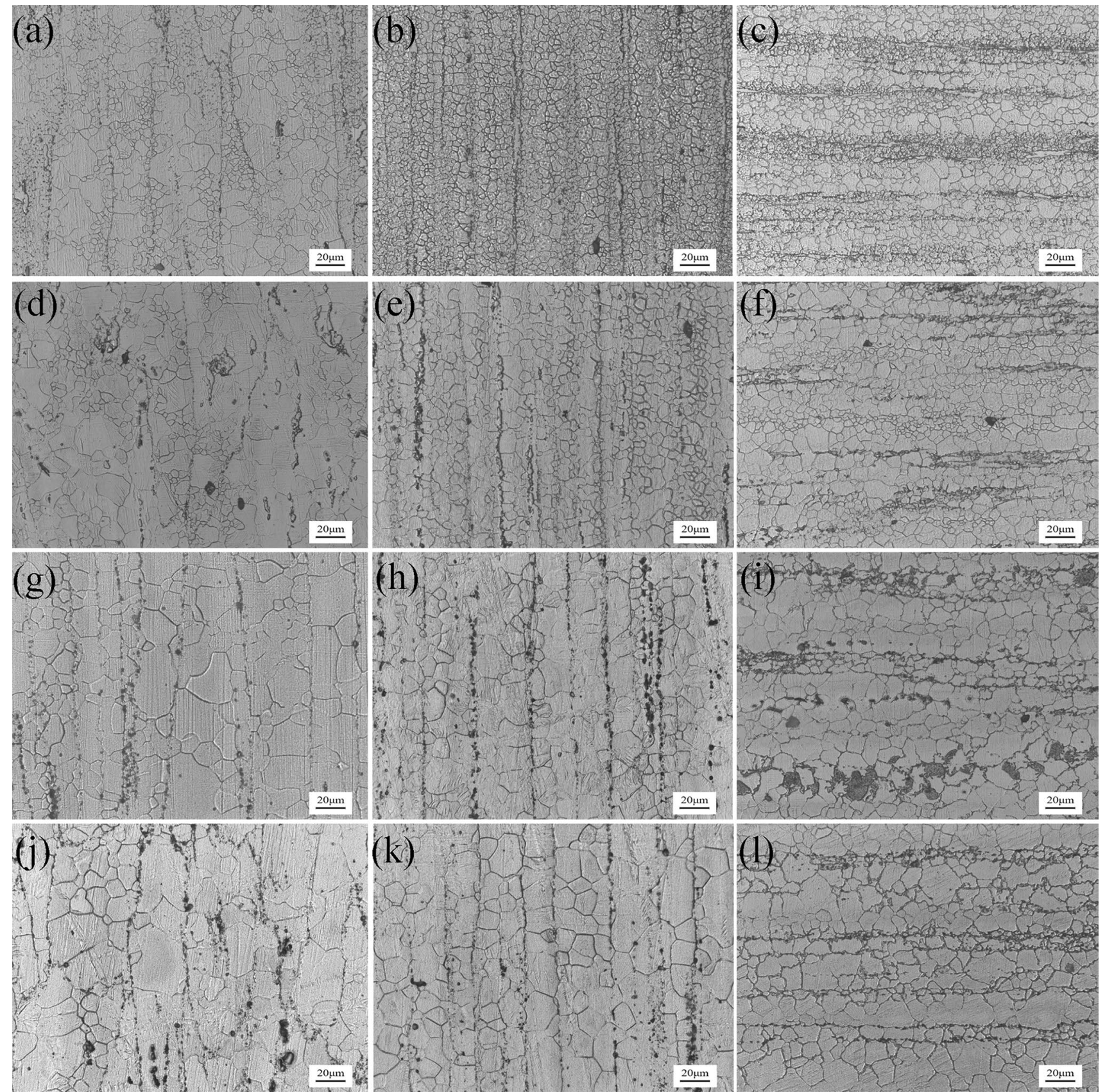

Fig. 6 Optical microscopes of the different zones of the recycled-extrusion billets at different temperatures: a CRZ/300 ${ }^{\circ} \mathrm{C}, \mathbf{b} \mathrm{ESZ} / 300{ }^{\circ} \mathrm{C}$, c SDZ/300 ${ }^{\circ} \mathrm{C}, \mathbf{d ~ C R Z / 3 5 0 ~}{ }^{\circ} \mathrm{C}, \mathbf{e ~ E S Z / 3 5 0 ~}{ }^{\circ} \mathrm{C}, \mathbf{f} \mathrm{SDZ} / 350{ }^{\circ} \mathrm{C}, \mathbf{g ~ C R Z} / 400{ }^{\circ} \mathrm{C}, \mathbf{h ~ E S Z} / 400{ }^{\circ} \mathrm{C}, \mathbf{i ~ S D Z} / 400{ }^{\circ} \mathrm{C}, \mathbf{j ~ C R Z / 4 5 0}{ }^{\circ} \mathrm{C}, \mathbf{k ~ E S Z} / 450{ }^{\circ} \mathrm{C}, \mathbf{l}$ $\mathrm{SDZ} / 450{ }^{\circ} \mathrm{C}$

The OM observations of the recycled-extrusion billets extruded at $400{ }^{\circ} \mathrm{C}$ with different extrusion velocities are illustrated in Fig. 8. The extrusion billets were ruptured as the extrusion velocity was increased to $1.4 \mathrm{~mm} / \mathrm{s}$, as illustrated in Fig. 2e. The coarse deformed grains (average grain size $>20 \mu \mathrm{m}$ ) were surrounded with the DRX grains (average grain size $<10 \mu \mathrm{m}$ ), and the coarse deformed grains and the strip $\beta$-phases were elongated along the ED in the CRZ.
The fraction of the DRX grains improved with the increase in the extrusion velocity, and the DRX grains mainly distributed around the line-distributed $\beta$-phases and bond interface. The elevated extrusion velocity can provide the additional driving force for DRX nucleation, and thus, the fraction of the DRX grains improved with the increase in extrusion velocity, as illustrated in Fig. 8a, d, g, j. The average size of the DRX grains decreased in the SDZ compared with that in 

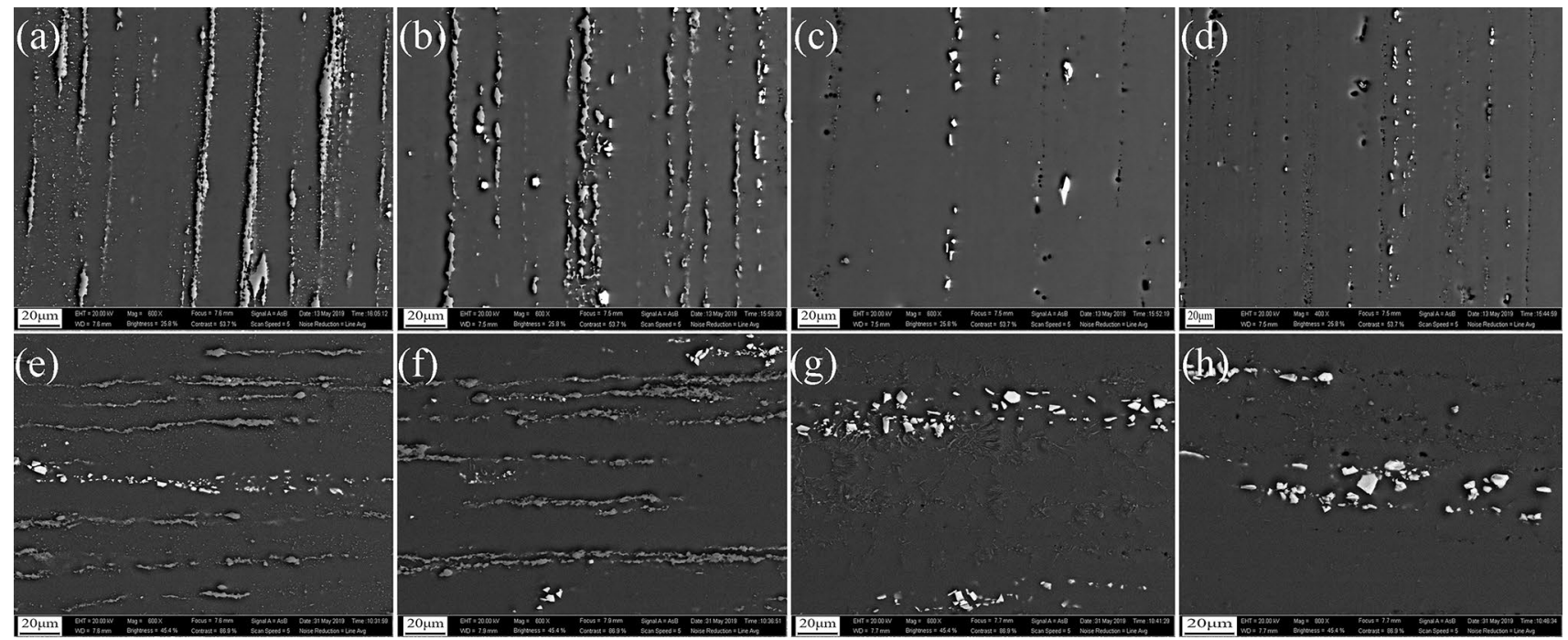

Fig. 7 SEM images of the ESZ and SDZ of the recycled-extrusion billets at different temperatures: a $\mathrm{ESZ} / 300{ }^{\circ} \mathrm{C}, \mathbf{b} \mathrm{ESZ} / 350{ }^{\circ} \mathrm{C}, \mathbf{c}$ $\mathrm{ESZ} / 400{ }^{\circ} \mathrm{C}, \mathbf{d} \mathrm{ESZ} / 450{ }^{\circ} \mathrm{C}$, e SDZ/300 ${ }^{\circ} \mathrm{C}$, f SDZ/350 ${ }^{\circ} \mathrm{C}$, g SDZ $/ 400{ }^{\circ} \mathrm{C}, \mathbf{h} \mathrm{SDZ} / 450{ }^{\circ} \mathrm{C}$

the CRZ and ESZ due to the additional shear strain, as demonstrated in Fig. 8c, f, i, 1. The average grain size at elevated extrusion velocity obviously decreased with the increase in the extrusion velocity. The elevated extrusion velocity indicated the shorter remaining time in the mold, and the growth of the finer DRX grains was partly restrained, and thus, the average grain size decreased.

The tensile properties of the recycled-extrusion billets with different extrusion parameters are shown in Fig. 9a, b. The recycled-extrusion billets extruded at $300{ }^{\circ} \mathrm{C}$ demonstrated the superior tensile strength and fracture elongation (FE), which can be ascribed to the finer DRX grains and homogeneous microstructure. The line-distributed strip $\beta$-phase and dispersive $\beta$-phase particles contribute to the superior tensile strength of the recycled-extrusion billets. Furthermore, the extrusion temperature slightly affects the tensile properties of the recycled-extrusion billets, as illustrated in Fig. 9a. As shown in Fig. 9b, the tensile yield strength (TYS) and ultimate tensile strength (UTS) decreased as the extrusion velocity increased to $1.0 \mathrm{~mm} / \mathrm{s}$ and $1.4 \mathrm{~mm} / \mathrm{s}$, which can be ascribed to the dissolution of the strip $\beta$-phases along the ED. The reduced strengthening effect of the strip $\beta$-phases results in the decreased TYS and UTS of the recycled-extrusion billets with extrusion velocity of $1.0 \mathrm{~mm} / \mathrm{s}$ and $1.4 \mathrm{~mm} / \mathrm{s}$. Meanwhile, the decreased fraction of the strip $\beta$-phases can reduce the inclination of the crack nucleation, and thus, the FE of the extrusion billets improved as the extrusion velocity increased to $1.4 \mathrm{~mm} / \mathrm{s}$.

The comparison between the tensile properties of the cast-extrusion and recycled-extrusion billets extruded at $400{ }^{\circ} \mathrm{C}$ with extrusion velocity of $0.6 \mathrm{~mm} / \mathrm{s}$ is illustrated in Fig. 9c. The tensile strength and the FE of the recycled billets were inferior to that of the cast billets; however, the recycled-extrusion billets demonstrated the comparable ultimate tensile strength and FE with the cast-extrusion billets. The holes or cracks were remained in the consolidation recycled billets, and the cracks were inclined to propagate adjacent to the holes or bond interface, which resulted in the inferior tensile properties of the consolidation recycled billets. The holes or cracks were hardly observed in the recycled-extrusion billets, which led to the comparable tensile strength and FE between the cast-extrusion (UTS-336 MPa, FE-19.8\%) and recycled-extrusion billets (UTS-334 MPa, FE-18.5\%). However, the bond interface between the metal chips can affect the TYS of the recycled-extrusion billets, and thus, the TYS of the recycled-extrusion billets was lower than that of the cast-extrusion billets.

The fracture morphologies of the recycled-extrusion billets and the cast-extrusion billets are illustrated in Fig. 10. In addition to the dimples, the obvious crack propagation trace can be observed in the fracture morphologies of the recycled-extrusion billets, as depicted in Fig. 10a, c, which might result from cracks propagation along the bond interface between the metal chips. However, only the tiny deep dimples were observed in the fracture morphology of the cast-extrusion billets, which indicated the ductile fracture mechanism. Although the integrated ES process can eliminate the cracks or holes at the bond interface between metal chips in the recycled-extrusion billets and the recycled-extrusion billets demonstrate the rival tensile properties compared with the cast-extrusion billets, the bond interface still affects the cracks nucleation and propagation during tension. 



Fig. 8 Optical microscopes of the different zones of recycled-extrusion billets at different extrusion velocities: a CRZ/0.2 mm/s, b ESZ/0.2 mm/s, c SDZ/0.2 mm/s, d CRZ/0.6 mm/s, e ESZ/0.6 mm/s, f SDZ/0.6 mm/s, g CRZ/1.0 mm/s, h ESZ/1.0 mm/s, i SDZ/1.0 mm/s, j $\mathrm{CRZ} / 1.4 \mathrm{~mm} / \mathrm{s}, \mathbf{k ~ E S Z} / 1.4 \mathrm{~mm} / \mathrm{s}, \mathbf{l ~ S D Z} / 1.4 \mathrm{~mm} / \mathrm{s}$

The consolidation recycled billets demonstrated the better compressive properties and inferior tensile properties compared with the cast billets, which indicated that the bond interface between the metal chips demonstrated weaker bond properties during tension process. The cracks are inclined to nucleate and propagate adjacent to the bond interface between the metal chips during tension; thus, the consolidation recycled billets present inferior tensile properties. The integrated ES forming process can eliminate the cracks or holes of the consolidation recycled billets due to its severe plastic deformation, and thus, the recycled billets after integrated ES forming demonstrated the rival tensile properties compared with the cast-extrusion billets. The lower extrusion temperature and elevated extrusion velocity facilitate obtaining the homogeneous 

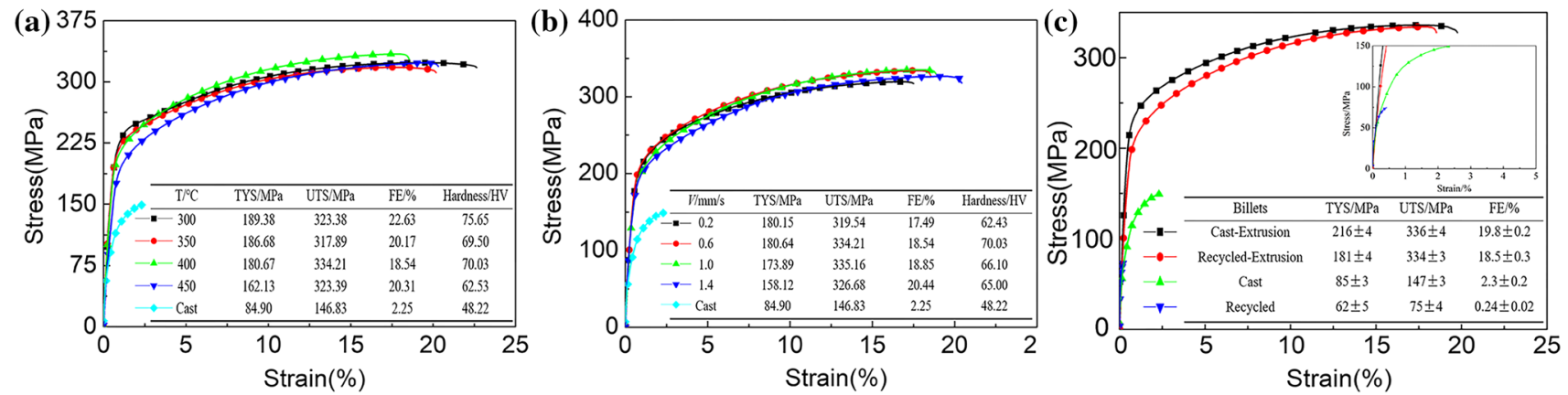

Fig. 9 Tensile stress-strain curves of $\mathbf{a}$ the recycled billets after integrated ES forming at different extrusion temperatures, $\mathbf{b}$ at different extrusion velocities, $\mathbf{c}$ the cast-extrusion and recycled-extrusion billets


Fig. 10 Fracture morphologies of $\mathbf{a}, \mathbf{c}$ the recycled-extrusion billets, $\mathbf{b}, \mathbf{d}$ cast-extrusion billets

finer DRX grains. Furthermore, the cracks propagation along the bond interface in the fracture of the recycled-extrusion billets indicates that the bond interface still affects the crack nucleation and propagation during tension although the recycled-extrusion billets demonstrate the rival tensile properties compared with the cast-extrusion billets.

\section{Conclusions}

The consolidation AZ80 billets were successfully recycled in this study. The integrated ES forming was also implemented on the consolidation recycled billets. The main conclusions are listed as follows: 
1. The AZ80 metal chips are successfully consolidation recycled through the cold press and hot press sintering process. The recycled billets sintered at $350{ }^{\circ} \mathrm{C}$ demonstrate the better compressive properties (UCS$360.51 \mathrm{MPa}, \mathrm{CFS}-14.08 \%$ ) and, however, present the inferior tensile properties (UTS-75 MPa, FE—0.24\%) during tension.

2. The ultimate tensile strength and facture elongation of the consolidation recycled billets are significantly improved to $334 \mathrm{MPa}$ and $18.5 \%$, respectively, after integrated ES process. The homogeneous finer DRX grains with an average grain size of $6 \mu \mathrm{m}$ can be obtained in the shear deformation zone and extrusion sizing zone through integrated ES process at $300{ }^{\circ} \mathrm{C}$ with an extrusion velocity of $0.6 \mathrm{~mm} / \mathrm{s}$.

3. The lower extrusion temperature and elevated extrusion velocity facilitate the formation of homogeneous finer DRX grains. The finer DRX grains grow up as the extrusion temperature increases.

4. The recycled-extrusion billets demonstrate the rival tensile properties (UTS-334 MPa, FE-18.5\%) compared with the cast-extrusion billets (UTS-336 MPa, FE-19.8\%). The holes or cracks in the consolidation recycled billets can be nearly eliminated through the integrated ES process, which results in the rival tensile properties of the recycled-extrusion billets. However, the remained defects still slightly affect the tensile properties and crack propagation along the bond interface during tension.

Acknowledgements This work is financially supported by the National Natural Science Foundation of China (No. 51875127).

\section{References}

[1] R.G. Li, F. Asghar, J.H. Zhang, G.Y. Fu, Q. Liu, B.T. Guo, Y.M. Yu, S.G. Guo, Y. Su, X.J. Chen, L. Zhong, Acta Metall. Sin. (Engl. Lett.) 32, 245 (2019)
[2] K.K. Alaneme, E.A. Okotete, J. Magnes. Alloys 5, 460 (2017)

[3] B. Li, B.G. Teng, G.X. Chen, Mater. Sci. Eng. A 744, 396 (2018)

[4] L.X. Wang, R.B. Song, C.H. Cai, J.Y. Li, Acta Metall. Sin. (Engl. Lett.) 32, 10 (2019)

[5] B. Li, B.G. Teng, D.G. Luo, Acta Metall. Sin. (Engl. Lett.) 31, 1009 (2018)

[6] B.B. Wan, W.P. Chen, T.W. Lu, F.F. Liu, Z.F. Jiang, M.D. Mao, Resour. Conserv. Recycl. 125, 37 (2017)

[7] B. Li, B.G. Teng, W.C. Xu, JOM 71, 4059 (2019)

[8] A. Razi, K.M. Habid, Resour. Conserv. Recycl. 110, 30 (2016)

[9] E. Calvert, B. Wynne, N. Weston, A. Tudball, M. Jackson, J. Mater. Process. Technol. 254, 158 (2018)

[10] M. Mamoru, K. Kohei, H. Kenji, Mater. Trans. 36, 1249 (1995)

[11] K. Kuzman, I. Kacmarcik, T. Pepelnjak, M. Plancak, D. Vilotic, J. Prod. Eng. 15, 79 (2012)

[12] Q. Liu, X. Zhou, H.T. Zhou, X.H. Fan, K.M. Liu, J. Magnes. Alloys 5, 202 (2017)

[13] S.H. Wei, M.L. Hu, Z.S. Ji, H.Y. Xu, Y. Wang, Mater. Sci. Technol. 34, 2097 (2018)

[14] Y. Zhu, M.L. Hu, D.J. Wang, H.Y. Xu, Y. Wang, Z.S. Ji, Mater. Sci. Technol. 34, 876 (2018)

[15] M.A. Thein, L. Lu, M.O. Lai, Compos. Struct. 75, 206 (2006)

[16] Z.S. Ji, L.H. Wen, X.L. Li, J. Mater. Process. Technol. 209, 2128 (2009)

[17] A.R. Anilchandra, M.K. Surappa, Mater. Sci. Eng. A 560, 759 (2013)

[18] Y. Chino, K. Kishihara, K. Shimojima, H. Hosokawa, Mater. Trans. 43, 2437 (2002)

[19] Y. Chino, T. Hoshika, J.S. Lee, M. Mabuchi, J. Mater. Res. 21, 754 (2006)

[20] Y. Chino, J.S. Lee, Y. Nakaura, K. Ohori, M. Mabuchi, Mater. Trans. 46, 2592 (2005)

[21] D. Orlov, G. Raab, T.T. Lamark, M. Popov, Y. Estrin, Acta Mater. 59, 375 (2011)

[22] D. Orlov, K.D. Ralston, N. Birbilis, Y. Estrin, Acta Mater. 59, $6176(2011)$

[23] A. Vinogradov, D. Orlov, Y. Estrin, Scr. Mater. 67, 209 (2012)

[24] T. Peng, Q.D. Wang, Y.K. Han, J. Zheng, W. Guo, J. Alloys Compd. 503, 253 (2010) 